\title{
REVISÃO SOBRE TÉCNICAS E TRATAMENTOS DE ÁGUAS PARA REUSO DOMÉSTICO
}

\author{
Andressa D’Agostin ${ }^{1}$, Valter Antônio Becegato ${ }^{2}$,Camila Angélica Baum ${ }^{1}$
}

(1 - Universidade do Estado de Santa Catarina, Mestranda em Ciências Ambientais, andressa.dg94@gmail.com; eng.camilabaum@gmail.com; 2 - Universidade do Estado de Santa Catarina, Professor Associado da Universidade do Estado de Santa Catarina, valter.becegato@udesc.br)

Resumo: A problemática da água como recurso cada vez mais finito,suscita estudos acerca de alternativas para o tratamento das águas geradas em residências (negras e cinzas), assim como as pluviais, de forma que a sua qualidade final seja tal que possibilite o seu emprego como fonte alternativa para fins não potáveis. O presente trabalho objetivou revisar estudos que abordassem diferentes tratamentos para águas servidas domiciliares e pluviais para reuso em fins domésticos não potáveis, comparando sua eficiência com a normativa brasileira. Nesse contexto, faz-se necessária a adoção de medidas que visem à redução de consumo e conservação dos recursos hídricos disponíveis, o que implica na conscientização e mudança de hábitos por parte dos usuários.

Palavras-chave: Tratamento de efluentes domésticos. Águas cinzas. Águas pluviais. Reuso de água.

\section{REVISION ON WATERS TREATMENT AIMING DOMESTIC WATER REUSE}

Abstract: The problem of water as a(n) (increasingly) finite resource demands a study on alternatives to treat domestic effluent (black and graywater), as well as rainwater, considering its final quality is such that allows its usage as an alternative source for nonpotable ends. The present work aimed to revise studies on different treatment for domestic wastewaters and rainwater for nonpotable reuse in domestic purposes, comparing its efficiency with the Brazilian norm. Therefore, it is imperative that measures focused on reducing its consumption and saving available drinking water are adopted, which demands users to develop consciousness and change some habits.

Keywords: Domestic wastewater treatment. Greywater. Rainwater. Water reuse.

\footnotetext{
Artigo recebido para publicação em 15 de Março de 2017 Artigo aprovado para publicação em 03 de Junho de 2017
} 


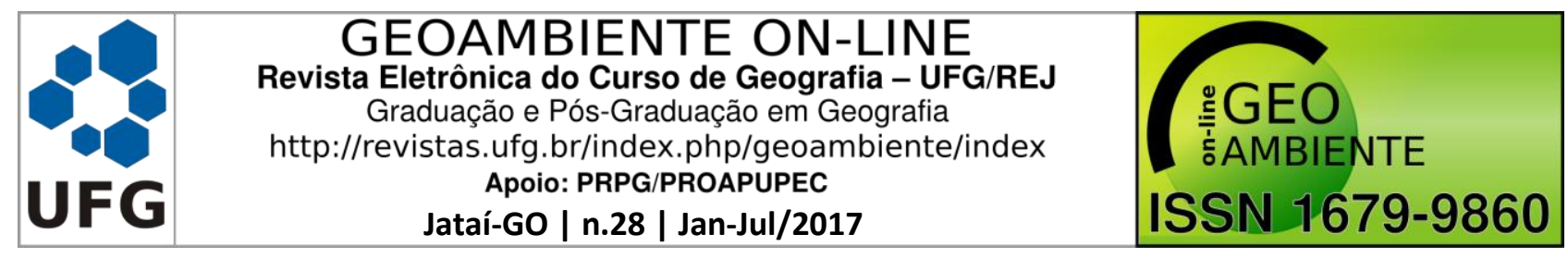

\section{REVISIÓN SOBRE TRATAMIENTO DEAGUA PARA SU REUTILIZACIÓN DOMÉSTICA}

Resumen: El problema del agua como un recurso (cada vez más) finito hace necesario un estudio sobre alternativas para el tratamiento de las aguas generadas en casa (negras y grises), así como el agua de lluvia, presentando calidad final tal que permita su uso como una fuente alternativa para fines no potables. Este estudio tuvo como objetivo revisar estudios que abordaron diferentes tratamientos para aguas residuales domesticasy pluviales para su reutilización en usos domésticos de agua no potable, comparando su eficacia con las regulaciones brasileñas. En este contexto, es necesario adoptar medidas encaminadas a reducir el consumo y la conservación de los recursos hídricos disponibles, que implica la toma de conciencia y el cambio de hábitos de los usuarios.

Palabras clave: Tratamiento de aguas residuales domésticas. Aguas grises. Agua de lluvia. Reutilización del agua.

\section{Introdução}

A contaminação dos cursos d'água pela emissão de efluentes domésticos e industriais é um problema recorrente e atualmente não se restringe somente aos grandes centros urbanos. Contudo, a construção das estações de tratamento de efluentes não tem acompanhado o aumento do volume de efluentes gerados, causando a degradação da maioria dos cursos d'água. De acordo com Philippi Jr. \& Malheiros (2005), devido ao considerável acréscimo populacional, historicamente gerado pela Revolução Industrial e as mudanças por ela trazidas, houve, consequentemente, um aumento da demanda por infraestrutura, principalmente em ações de saneamento do meio, embora os investimentos não tenham conseguido acompanhar as necessidades.

Segundo o Diagnóstico dos Serviços de Água e Esgotos de 2014, realizado pelo Sistema Nacional de Informações sobre Saneamento (SNIS), 49,8\% dos esgotos gerados no país são coletados. Destes, 70,9\% são tratados (BRASIL, 2016). Considerando tal situação, e sabendo que dois terços da população mundial enfrentam uma severa escassez de água ao menos um mês por ano, sendo que 500 milhões de pessoas sofrem com a escassez o ano todo (MEKONNEN \& HOEKSTRA, 2016), é imperativa a adoção de atitudes para reduzir o consumo e o desperdício dos recursos hídricos disponíveis, através da conscientização da população e da adoção de hábitos de conservação da água. 


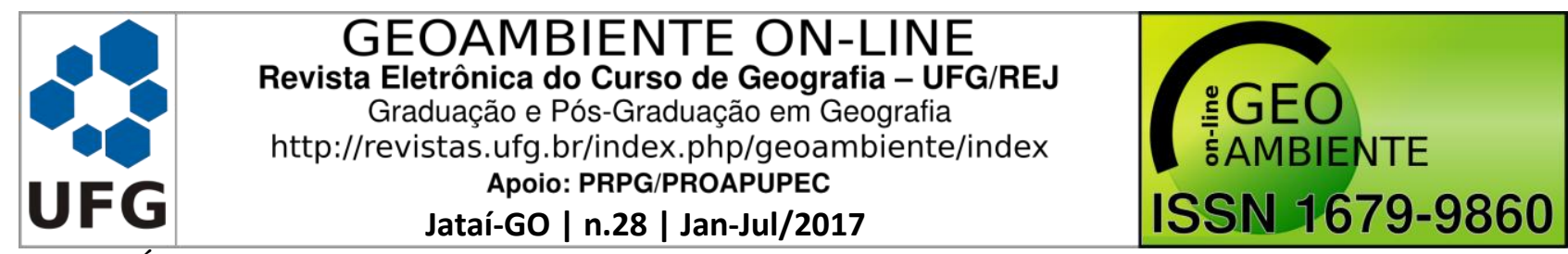

É neste cenário que se insere o reuso da água, que vem sendo empregado como medida de redução do consumo de fontes potáveis, que devem estar disponíveis para usos mais nobres: aqueles que envolvam contato pessoal direto, interno ou externo, assim como a dessedentação animal. Além disso, a redução do uso da água potável também é uma forma de minimizar os impactos ambientais e os custos relacionados a projetos de estações de tratamento de água, de transposições interbacias hidrográficas e de estações de tratamento de esgoto, por exemplo (HESPANHOL, 2008).

Nesse sentido, este trabalho teve como objetivo pesquisar por meio de estudos publicados, as diferentes técnicas de reuso doméstico de águas (cinzas, negras e pluviais) existentes e verificar os métodos de tratamento utilizados, de forma a contemplar o exigido por normas e legislação para uso em fins não potáveis, além de definir o potencial de reuso para as águas cinzas, negras e pluviais, depois de tratadas.

\section{Material e métodos}

Foram consultados diversos estudos como dissertações, teses, monografias, trabalhos de conclusão de curso, manuais, livros, artigos de revistas e periódicos, bem como a legislação e normas técnicas brasileiras pertinentes ao assunto. Dessa forma, foram utilizadas as bases de dados da Biblioteca Digital de Teses e Dissertações (BDTD) e o Google Acadêmico. Foram utilizadas as palavras-chave: "reuso", "água","doméstico" e "águas cinzas". Adotou-se como parâmetro para a pesquisa bibliográfica trabalhos publicados dos nos últimos 15 anos entre 2001 a 2016.

A busca no Google Acadêmico encontrou 1.820 resultados no total, dentre os quais estavam alguns materiais cujo enfoque era distinto de tratamentos domiciliares de efluentes e reuso de água exclusivamente em residências. Já a busca na Biblioteca Digital de Teses e Dissertações resultou em108 trabalhos na área. Destes, foram selecionados 30 trabalhos que apresentavam pelo menos um método de tratamento para algum tipo de água gerada por atividades domésticas, visando o reuso das mesmas.Além disso, foram excluídos os trabalhos, tanto do BDTD e Google Acadêmico, que não apresentavam sistemas de tratamento com dimensões condizentes para adoção em residências, assim como os que tratavam de usos não domésticos (indústrias, reuso urbano, fertirrigação/agrícola, em universidades etc.), ou apenas apresentavam uma avaliação (qualitativa ou quantitativa) do reuso, sem sugerir tratamento ou apresentar a eficiência do mesmo. 
Os trabalhos analisados foram também comparados com a norma NBR n.13969

(ABNT, 1997), que dispõe sobre projeto, construção e operação de unidades de tratamento complementar e disposição final dos efluentes líquidos, a fim de classificar os usos.

\section{Resultados e discussão}

A partir da leitura dos 30 trabalhos referentes a diversos tratamentos de águas domésticas com vistas ao reuso para fins não potáveis em residências, os dados foram tabulados em forma de quadro, para facilitar a comparação dos resultados. Além disso, a eficiência dos tratamentos foi analisada em concordância com os padrões da norma NBR n. 13969 (ABNT, 1997) estabelecidos para águas reusadas em fins não potáveis, exceto para os trabalhos que não incluíam caracterização do efluente tratado.

A partir da análise do Quadro 1, constatou-se que apenas três autores (10\%)empregaram caixa de gordura como pré-tratamento em seus trabalhos, devido principalmente ao tipo de água que foi tratada: a caixa de gordura tem como função a retenção de gorduras, que, em uma residência, estão presentes nas águas de lavagens de louças - águas cinza-escuras ou negras. No total, seis autores (20\%) fizeram uso de outras técnicas de prétratamento, que incluíam também gradeamento, peneira e caixa de sedimentação para sólidos em suspensão e sólidos maiores.

A maioria dos trabalhos num total de 60\%optou por alguma etapa de filtração, utilizando diversos meios filtrantes, como areia de diferentes granulometrias, carvão ativado, pedra brita, e outros mais alternativos, como anéis de bambu e cascas de coco verde; filtros que incluíam tratamento biológico principalmente anaeróbicos também foram bastante utilizados no total $20 \%$, além de outras configurações, como wetlands construídos 23,3\% e biodiscos aerados.

Os trabalhos cujos tratamentos apresentados não incluíam desinfecção não se mostraram tão eficientes, segundo parâmetros estabelecidos pela norma NBR n. 13969 (ABNT, 1997) ou pelo Manual da ANA (2005), ressaltando em suas conclusões a importância da inclusão de uma etapa com tal finalidade. O desinfetante mais utilizado foi o cloro, na forma de hipoclorito de sódio, por sua facilidade de manuseio e aquisição.

Contudo, uma característica indesejada das águas cinzas armazenadas é o mau odor, ocasionado pela redução dos sulfatos a sulfetos e liberação do gás sulfídrico $\left(\mathrm{H}_{2} \mathrm{~S}\right)$; tal redução ocorre em meios anaeróbios, evidenciando um ponto positivo do uso de sistemas aeróbios, como o empregado por Bazzarella (2005). 
Quadro 1 - Tratamento realizado para diferentes tipos de águas, seu reuso sugerido e enquadramento na norma NBR n.13969 (ABNT, 1997).

\begin{tabular}{|c|c|c|c|c|}
\hline Tratamento & Tipo de água & Uso sugerido & Autor(es) & $\begin{array}{l}\text { Atendimento aos } \\
\text { parâmetros } \\
\text { (NBR 13969) } \\
\end{array}$ \\
\hline $\begin{array}{c}\text { CS + FAFA (brita) + Filtro } \\
(\text { areia) + Desinfecção (cloro) }\end{array}$ & $\begin{array}{l}\text { AC chuveiros } \\
\text { e pias }\end{array}$ & $\begin{array}{l}\text { Descargas em bacias } \\
\text { sanitárias }\end{array}$ & $\begin{array}{l}\text { Rapoport } \\
(2004)\end{array}$ & Sim \\
\hline $\begin{array}{c}\mathrm{RAC}+\mathrm{FBAS}+\mathrm{FT}+ \\
\text { Desinfecção (cloro) }\end{array}$ & $\mathrm{AC}$ & $\begin{array}{c}\text { Descargas em bacias } \\
\text { sanitárias }\end{array}$ & $\begin{array}{c}\text { Bazzarella } \\
(2005)\end{array}$ & Sim \\
\hline TS + Wetlands & $\mathrm{AC}+\mathrm{AP}$ & $\begin{array}{l}\text { Fins domésticos não } \\
\text { potáveis* }\end{array}$ & $\begin{array}{l}\text { Ferreira } \\
(2005)\end{array}$ & - \\
\hline $\begin{array}{c}\text { TS (3 compartimentos em } \\
\text { série) + Wetlands + PF + } \\
\text { Filtração lenta** }\end{array}$ & $\begin{array}{l}\text { ARD + águas } \\
\text { laboratórios e } \\
\text { oficina } \\
\text { mecânica }\end{array}$ & Irrigação & $\begin{array}{l}\text { Marrara } \\
(2005)\end{array}$ & Sim (Classe 4) \\
\hline $\begin{array}{c}\text { Filtração (areia) + } \\
(\text { Desinfecção (cloro) AC) }\end{array}$ & $\mathrm{AC}+\mathrm{AP}$ & $\begin{array}{l}\text { Fins domésticos não } \\
\text { potáveis* }\end{array}$ & $\begin{array}{l}\text { Philippi et al. } \\
\qquad(2005)\end{array}$ & Sim \\
\hline $\begin{array}{c}\text { AC: Filtro (pedra) + } \\
\text { Desinfecção (cloro)/AP: } \\
\text { Tanque descarte + Filtro } \\
(\text { areia) }=\text { Tanque mistura } \\
\text { (AC+AP) }\end{array}$ & $\mathrm{AC}$ e $\mathrm{AP}$ & $\begin{array}{l}\text { Descargas em bacias } \\
\text { sanitárias }\end{array}$ & Peters (2006) & Sim \\
\hline $\begin{array}{l}\text { MBR módulo membrana } \\
\text { submersa }\end{array}$ & ARD & $\begin{array}{c}\text { Fins domésticos não } \\
\text { potáveis* }\end{array}$ & $\begin{array}{l}\text { Maestri } \\
(2007)\end{array}$ & Sim (Classe 1) \\
\hline $\begin{array}{c}\text { Lodos ativados + Filtração } \\
\text { (leito fixo }- \text { areia/CP/AdC + } \\
\text { óxidos } \mathrm{Fe})+\mathrm{POA} \\
\left(\mathrm{UV} / \mathrm{H}_{2} \mathrm{O}_{2} / \mathrm{Fe}^{3+}\right)\end{array}$ & ARD & $\begin{array}{l}\text { Fins domésticos não } \\
\text { potáveis* }\end{array}$ & $\begin{array}{l}\text { Vargas } \\
(2008)\end{array}$ & Sim \\
\hline $\begin{array}{c}\mathrm{CG}+\mathrm{CS}+\text { Wetlands-FH }+ \text { TI } \\
+ \text { Wetlands-FV }\end{array}$ & $\mathrm{ACE}$ & $\begin{array}{l}\text { Fins domésticos não } \\
\text { potáveis* e irrigação } \\
\text { restrita (WHO, 2006) }\end{array}$ & $\begin{array}{l}\text { Begosso } \\
(2009)\end{array}$ & Sim \\
\hline $\begin{array}{c}\text { Separação por membranas } \\
\text { ativadas (Japão) }\end{array}$ & ARD & $\begin{array}{c}\text { Descargas em bacias } \\
\text { sanitárias }\end{array}$ & Braga (2009) & - \\
\hline $\begin{array}{c}\text { Peneira + Sedimentação + } \\
\text { Filtração (areia) + } \\
\text { Desinfecção (cloro) }\end{array}$ & AP & $\begin{array}{l}\text { Fins domésticos não } \\
\text { potáveis* }\end{array}$ & May (2009) & Sim \\
\hline Wetlands & $\mathrm{AC}$ & $\begin{array}{l}\text { Fins domésticos não } \\
\text { potáveis* }\end{array}$ & $\begin{array}{l}\text { Monteiro } \\
(2009)\end{array}$ & Sim \\
\hline $\begin{array}{c}\text { Grade + RAC + FBAS + } \\
\text { Decantação + TQE + FT + } \\
\text { Desinfecção (cloro) }\end{array}$ & $\mathrm{AC}$ & $\begin{array}{l}\text { Fins domésticos não } \\
\text { potáveis* }\end{array}$ & Pertel (2009) & - \\
\hline $\begin{array}{c}\text { RAC + FBAS + Decantação + } \\
\text { TQE + FT + Desinfecção } \\
\text { (cloro) }\end{array}$ & $\mathrm{AC}$ & $\begin{array}{l}\text { Fins domésticos não } \\
\text { potáveis* }\end{array}$ & Vaz (2009) & Sim (Classe 3) \\
\hline $\begin{array}{c}\text { RAC + FBAS + Decantação + } \\
\text { TQE + FT + Desinfecção } \\
\text { (cloro) }\end{array}$ & $\mathrm{AC}$ & $\begin{array}{l}\text { Fins domésticos não } \\
\text { potáveis* }\end{array}$ & $\begin{array}{l}\text { Valentina } \\
(2009)\end{array}$ & Sim \\
\hline $\begin{array}{c}\mathrm{TQE}+\mathrm{RCB} * * *+\text { Decantação } \\
\text { secundária + Filtração + } \\
\text { Desinfecção (cloro) }\end{array}$ & $\mathrm{AC}$ & $\begin{array}{l}\text { Fins domésticos não } \\
\text { potáveis* }\end{array}$ & $\begin{array}{c}\text { May\& } \\
\text { Hespanhol } \\
\text { (2008 apud } \\
\text { Sella, 2011); } \\
\text { May (2009) } \\
\end{array}$ & Sim \\
\hline $\begin{array}{c}\text { CS + Filtro lento (brita e } \\
\text { areia) + Desinfecção (UV) }\end{array}$ & $\mathrm{AC}$ & $\begin{array}{c}\text { Fins domésticos não } \\
\text { potáveis* }\end{array}$ & $\begin{array}{l}\text { Nirenberg\& } \\
\text { Reis (2010) }\end{array}$ & Não \\
\hline
\end{tabular}




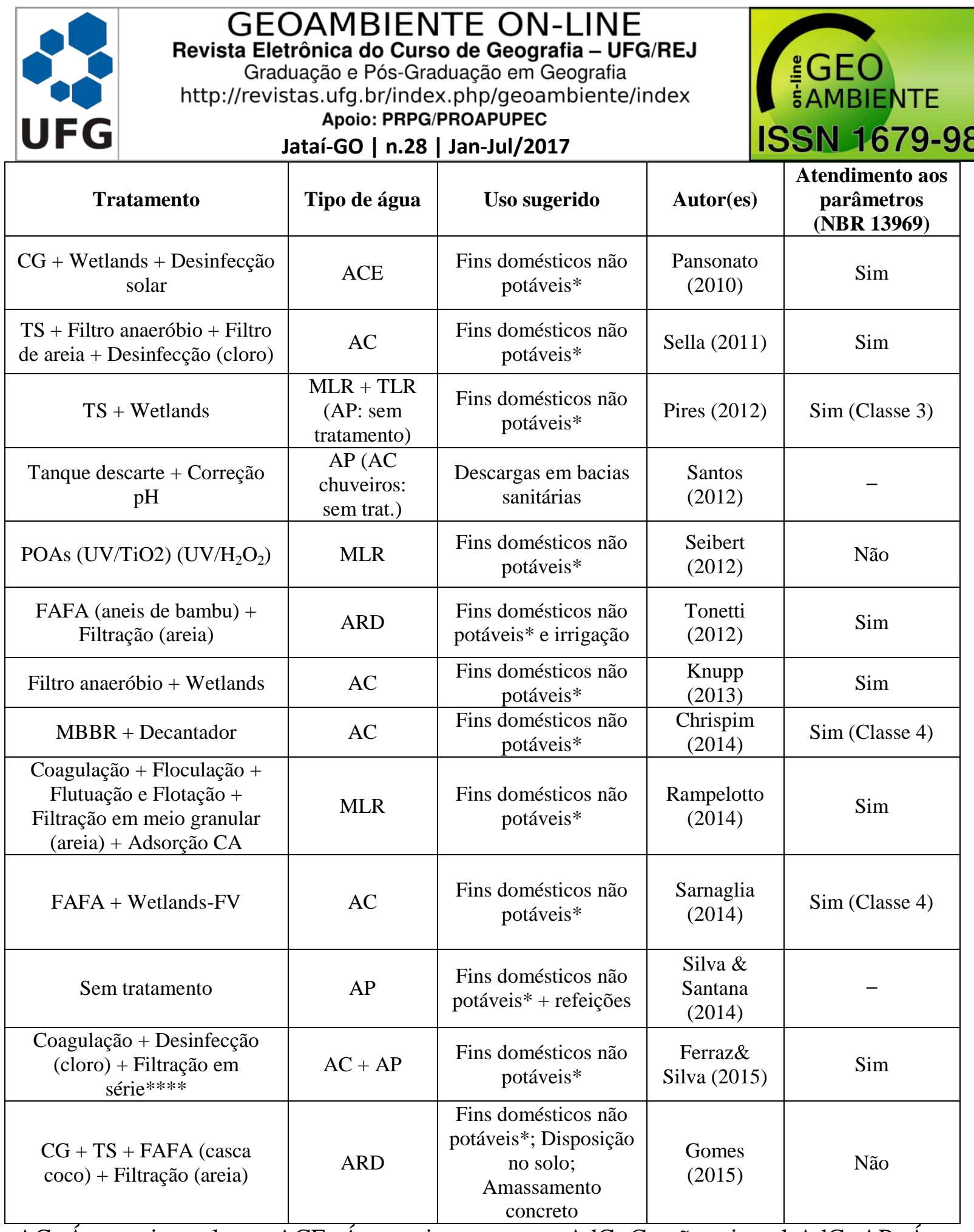

AC: Águas cinza-claras; ACE: Águas cinza-escuras; AdC: Carvão mineral AdC; AP: Águas pluviais; ARD: Águas residuárias domésticas; CA: Carvão ativado (pós-tratamento); CG: Caixa de gordura; CS: Caixa de sedimentação para sólidos em suspensão e sólidos maiores; CP: Carbotrat Premium; FAFA: Filtro biológico anaeróbio de fluxo ascendente; FBAS: Filtro Biológico Aerado Submerso; FH: Fluxo horizontal; FT: Filtro Terciário; FV: Fluxo vertical; MBR: Biorreator com membranas; MLR: Máquina lavar roupas; PF: Pré-filtro de fluxo ascendente; RAC: Reator Anaeróbio Compartimentado; TI: Sistema intermitente de abastecimento; TLR: Tanque lavar roupas; TQE: Tanque de Equalização de Vazão; TS: Tanque séptico.

* Rega de jardins, descarga em bacias sanitárias, lavagem de: veículos, roupas, pisos, calçadas.

** Dois filtros lentos em paralelo, de areia e manta sintética não tecida e de areia com CA e manta sintética não tecida. 
*** Reator Biológico de Contato (Biodiscos; Tratamento biológico aeróbio).

**** 3 filtros com diferentes camadas (areia, cerâmica e carvão).

Foi possível observar que $16,67 \%$ dos trabalhos usaram as águas tratadas restritamente para descargas em bacias sanitárias, possivelmente por conta do volume ofertado suprir somente esta demanda em uma residência. Apenas 6,67\% dos trabalhos analisaram a qualidade das águas comparativamente com os requisitos da Organização Mundial da Saúde (WHO, 2006) para irrigação de espécies alimentícias, apresentando qualidade satisfatória para tal uso.

Dos dois trabalhos correspondente a $6,67 \%$ que utilizaram Processos Oxidativos Avançados, o estudo realizado por Seibert (2012) empregado POAs para o tratamento de águas exclusivamente de máquinas de lavar roupas, mostrou disparidades entre as duas configurações: o processo utilizando $\mathrm{UV} / \mathrm{H}_{2} \mathrm{O}_{2}$ não se mostrou eficiente para a remoção de matéria orgânica, ao contrário da aplicação de $\mathrm{UV} / \mathrm{TiO}_{2}$, que mineralizou aproximadamente 90\% do total nas amostras testadas; contudo, ambos os processos acidificaram as amostras, acarretando em restrições para seu uso, mesmo em fins não potáveis. Além disso, houve um aumento da toxicidade do efluente tratado em comparação com o bruto em ambas as configurações.

Por outro lado, Vargas (2008) utilizou POA (Processo Fenton: UV/ $\mathrm{H}_{2} \mathrm{O}_{2} / \mathrm{Fe}^{3+}$ ) como tratamento terciário de efluente, após a passagem por filtro adsortivo com carvão mineral, com diferentes fluxos (tendo o ascendente obtido melhores resultados que o descendente),sendo que o processo mostrou-se eficiente para a destruição das células de Escherichia coliapós 60 minutos de reação, com a inativação de cerca de $97 \%$ das células bacterianas, tendo seu desempenho atribuído ao uso do agente oxidante (peróxido de hidrogênio) e do $\mathrm{Fe}^{3+}$.

O tratamento com coagulantes e desinfetantes utilizado por Ferraz \& Silva (2015), apresentou resultado satisfatório na redução significativa de turbidez, coloração, cloretos e coliformes totais. Contudo, verificou-se um aumento no $\mathrm{pH}$ e na condutividade, indicando uma relação entre os dois parâmetros. Foi detectada a presença de sulfatos no efluente de saída do tanque, ocasionada pelo uso de sulfato de alumínio como coagulante, cujo processo de filtração remove boa parte do componente, estando a água dentro dos padrões exigidos pelas legislações.

Dessa forma, a utilização de agentes coagulantes orgânicos biodegradáveis, como os amidos em geral, deve ser incentivada, a fim de reduzir a dosagem empregada, ou até mesmo 


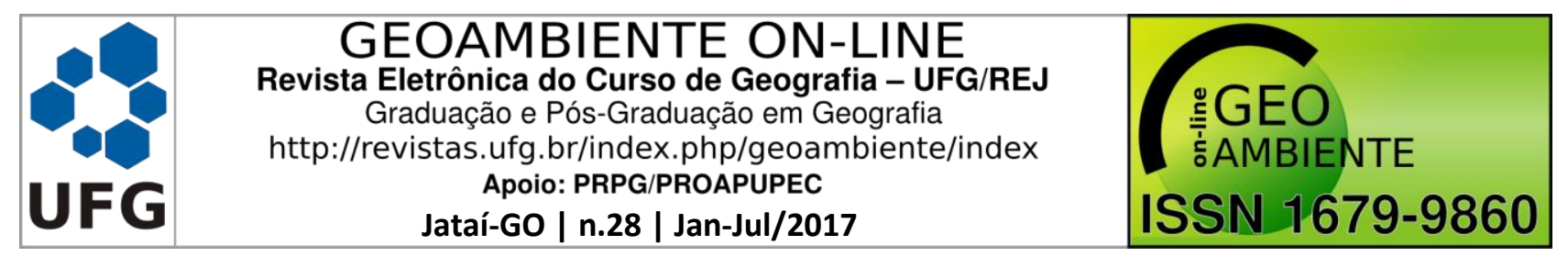

substituir os coagulantes convencionais como sulfato de alumínio ou férrico, produtos aos quais é atribuída a presença de metais no lodo gerado no processo de tratamento de água. Alguns exemplos são o amido natural de milho, que apresentou eficácia para remoção de cor aparente e turbidez de 70\% e 80\%, respectivamente (MURAKAMI \& MORUZZI, 2012) e os taninos, extraídos da casca de vegetais como a Acácia Negra - Acacia decurrens, que apresentaram redução de turbidez de 20,5 NTU da amostra bruta para 1,13 NTU da amostra tratada com $0,8 \mathrm{~mL} / \mathrm{L}$ de Tanfloc $\mathrm{SG}$, coagulante natural à base de tanino (ZOLETT, JABUR \& SILIPRANDI, 2012).

\section{Potencial de reuso}

Soares (1998) destaca que para a captação da água da chuva, é interessante aproveitar as estruturas já existentes na residência por questões de economia e facilidade.Neste sentido, pode-se utilizar a área do telhado ou laje e construir adicionalmente um sistema de calhas e um reservatório para que a água fique armazenada de forma a não entrar luz solar nem insetos. O sistema também deve ser projetado em concordância com o descrito na norma NBR n. 10.844 (ABNT, 1989), que dispõe sobre as instalações prediais de águas pluviais, para que estejam garantidos níveis adequados de segurança, funcionalidade, higiene, conforto, durabilidade e economia.

Além disso, deve-se lembrar de que a superfície do telhado não é um local limpo, podendo conter folhas e galhos de árvores, excretas de animais, material particulado como poeira, penas de pássaros, insetos e pequenos animais mortos (MAY, 2004). Portanto, para que a água da chuva possa ser utilizada como fonte alternativa, é necessário que haja "um controle da qualidade e a verificação da necessidade de tratamento, a fim de propiciar segurança à saúde do usuário e o não comprometimento da vida útil dos componentes do sistema de aproveitamento" (PETERS, 2006). Esse controle pode ser alcançado com a utilização de um sistema de descarte dos milímetros iniciais de precipitação, que servirá para a limpeza da atmosfera, da superfície de captação, assim como de calhas e tubulações da residência, somada à instalação de dispositivos de retenção de impurezas, como telas e filtros. Tomaz (1998 apud HAFNER 2007) recomenda que sejam rejeitados 0,4 a 1,5 mm por metro quadrado de área de captação.

Dixon et al., (1999 apud MAY, 2004) destacam que como forma de reduzir custos com obras e tratamento, é interessante considerar a realização da coleta e aproveitamento da água da chuva juntamente às águas cinza em um só reservatório, o que acarretaria benefícios à 


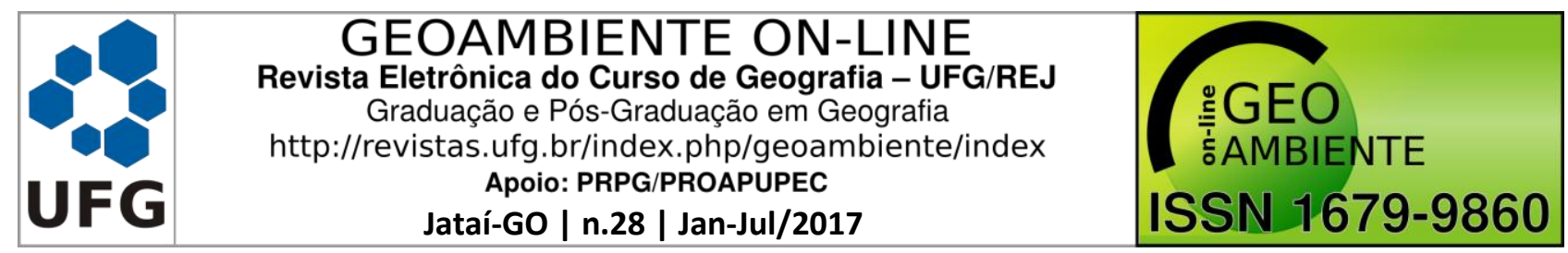

eficiência do sistema, como: volume de armazenamento reduzido, por conta da redução de água pluvial recebida em épocas de estiagem, além da redução de custos com tratamento, atribuída à diluição de contaminantes ocorrida por conta da mistura com as águas pluviais.

No geral, todos os tratamentos apresentaram alta eficiência para remoção de sólidos: sólidos suspensos totais, relacionados à turbidez; e sólidos dissolvidos, relacionados à cor verdadeira; porém a remoção de parâmetros biológicos não foi alcançada satisfatoriamente somente com processos físicos, reforçando a necessidade da etapa de desinfecção.O emprego de águas pluviais no preparo de refeições trazido por Silva \& Santana (2014), em seu artigo evidenciou uma realidade enfrentada por muitas famílias brasileiras como a falta do fornecimento de água encanada potável, restando-lhes como única alternativa a utilização de uma fonte restritamente indicada para fins não potáveis, por apresentar riscos de contaminação humana.

Para a avaliação do potencial de reuso das águas cinzas, negras e pluviais, foram analisados os resultados obtidos conforme o Quadro 1. As águas cinzas apresentaram maior emprego em fins domésticos não potáveis com 76,92\%, como rega de jardins, descarga em bacias sanitárias, lavagem de: veículos, roupas, pisos,calçadas.Os outros 23,08\%, referiam-se ao uso restrito em descargas sanitárias. O mesmo foi constatado para a mistura de águas cinzas e pluviais.

Já as águas negras ou Águas Residuárias Domésticas - ARD, apresentaram potencial para os dois usos explicitados acima, além do emprego na irrigação. As águas cinza-escuras foram utilizadas por dois autores, sendo que ambos os tratamentos apresentados por eles resultaram em um efluente tratado que atende aos parâmetros da norma NBR n.13.969 (ABNT, 1997) para uso em fins não potáveis.

Apenas três trabalhos não apresentaram tratamentos suficientemente eficientes para o reuso da água tratada, muito possivelmente por não conterem uma etapa para a desinfecção da mesma;ou então, como no caso de Niremberg \& Reis (2010), que utilizaram lâmpadas UV submersas, constataram que houve redução da sua eficiência por conta da formação de biofilme sobre a luva de quartzo. Além disso, Gomes (2015) atingiu os parâmetros requeridos pela norma NBR n.15900 (ABNT, 2009) para aplicação da água de reuso para amassamento de concreto e também para sua disposição no solo. Outro ponto interessante a ser observado foi a utilização de cascas de coco verde (Cocos nucifera) como meio suporte do Filtro Anaeróbio de Fluxo Ascendente, não agregando custo e ainda se apresenta como reutilização de um resíduo que seria descartado. 


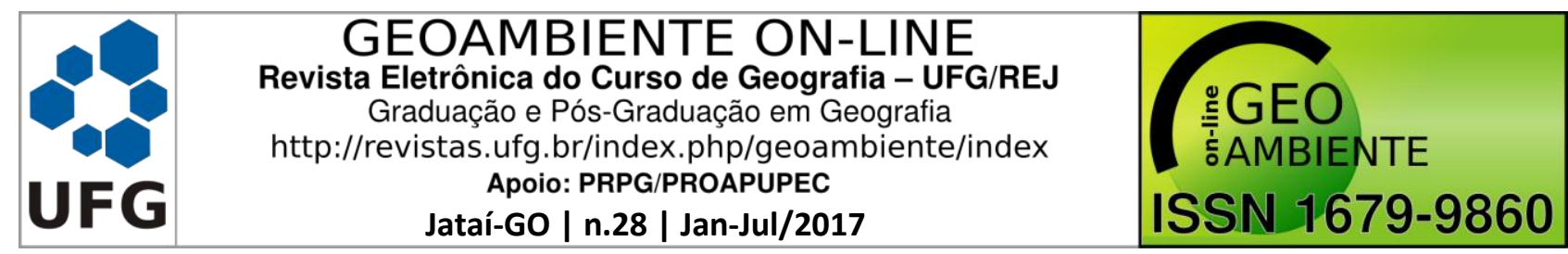

Como opção para os tratamentos sugeridos pelos autores estudados, é apresentado um método alternativo para substituí-los, também visando o posterior reuso das águas tratadas como a utilização da fossa de bananeiras ou tanque de evapotranspiração. Ele apresenta a vantagem de poder ser empregado tanto para águas negras, como para águas cinzas sejam elas claras ou escuras.

\section{Método alternativo}

Em contraponto ao sistema de fossa séptica e sumidouro comumente implantado em residências, que, de acordo com Souza (2008), não se configura como um tratamento eficiente, pois o processo se dá inteiramente sem a presença de oxigênio e considerando que o tratamento deve requerer o mínimo de espaço, produtos químicos e manutenção possíveis, uma sugestão feita pela Permacultura permite integrar biorremediação e paisagismo: a fossa de bananeiras, também chamada de tanque de evapotranspiração, é um sistema completo. Seguindo os princípios de tratamento empregados em sistemas wetlands construídos, o tanque de bananeiras associa a digestão anaeróbica a um canteiro séptico, onde, na zona de raízes das plantas, ocorre a digestão de toda a matéria orgânica, convertendo-a em biomassa viva, incluindo os frutos.

O tratamento consiste na decantação do efluente, sua posterior filtração, utilização dos nutrientes como o nitrogênio e fósforo pela planta e evapotranspiração da água tratada. Galbiati (2009), explica que a principal vantagem apresentada pelo sistema de tanque de evapotranspiração é a simplificação das etapas de pré-tratamento requerido pelas águas negras, já que o sistema "funciona como uma câmara de digestão anaeróbia, em sua parte inferior, e como um banhado construído [...], nas suas camadas intermediária e superior", além de as plantas absorverem totalmente o efluente, dispensando a necessidade de póstratamento.

Trata-se de uma caixa impermeável em alvenaria ou ferro-cimento, onde as águas negras serão tratadas por microrganismos e por filtração através da passagem por material filtrante, como pedras e areia, sendo posteriormente evapotranspiradas pelas espécies ali plantadas. Suas dimensões são calculadas de acordo com o volume de efluentes gerados pelos moradores da residência.

Após o tratamento, a água pode ser reutilizada em usos não potáveis, ou seguir para uma etapa de infiltração no solo por um jardim com argila expandida e/ou pedras, que servirão como drenos para a água. Quase totalmente tratado, o restante do efluente segue para um canteiro composto por plantas alimentícias e ornamentais. Espécies alimentícias sugeridas 


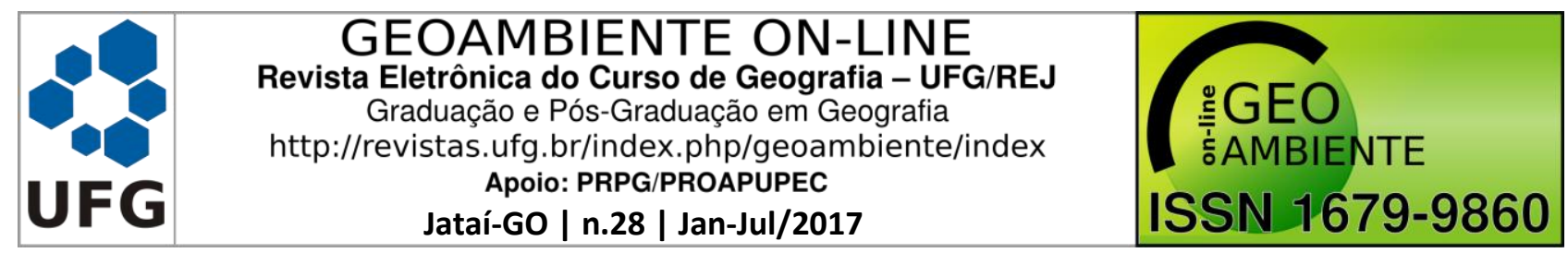

são hortaliças como couve e tomateiros, com restrição àquelas cujas raízes são consumidas cruas ou de crescimento rasteiro. Um exemplo deste tratamento é o empregado pela Casa dos Hólons, laboratório de Permacultura Urbana localizado em Campo Belo, São Paulo (SP).

\section{Considerações final}

As observações feitas neste trabalho, que teve como ponto de partida a problemática da água como recurso cada vez mais finito, permitiram concluir que a utilização de fontes alternativas de água em residências se configura como uma das soluções para tal problema. Há de se ressaltar a grande quantidade de trabalhos focados, principalmente, em reuso de água para indústrias e irrigação agrícola. Contudo, para que não haja riscos à saúde dos usuários, as águas servidas e/ou pluviais devem passar por algum tipo de tratamento e principalmente por desinfecção, para a eliminação dos microrganismos, que podem apresentar potencial patogênico, sendo sugerida a utilização de cloração.

Foi possível verificar que tanto as águas cinza-claras quanto escuras apresentaram potencial para reuso doméstico em fins não potáveis, assim como as águas pluviais, após passarem por tratamento e desinfecção. Apesar de pouco empregadas, as águas negras tratadas apresentaram potencial para aplicação na irrigação. Tais potenciais puderam ser definidos de acordo com a classificação definida pela norma NBR n.13969 (ABNT, 1997), que estabelece alguns padrões a serem atendidos.

Para a assimilação da prática do reuso pela sociedade, é importante que se tenham leis que regulamentem e estabeleçam parâmetros para as águas de reuso, de acordo com o uso que será dado a elas; além disso, a legislação principalmente a municipal, também se configura como incentivadora para aumentar a quantidade de edificações residenciais novas que já incorporem o reuso de água em seus projetos. Outras soluções são os incentivos relacionados à redução de impostos e tarifas para construções que apliquem o reuso, assim como programas de financiamento para implantação desse sistema em edificações residenciais existentes. Programas de conservação da água, essenciais para que haja um uso racional, devem contemplar a conscientização, a informação e a educação ambiental.

\section{Referências}

AGÊNCIA NACIONAL DE ÁGUAS. Federação das Indústrias do Estado de São Paulo. Sindicato da Indústria da Construção Civil do Estado de São Paulo. Conservação e Reuso da Água em Edificações. São Paulo: Prol Editora Gráfica, 152 p, 2005. 


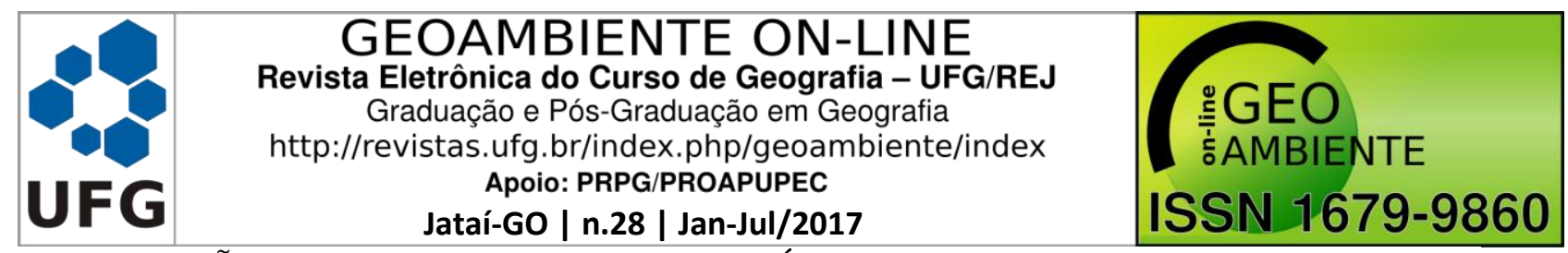

ASSOCIAÇÃO BRASILEIRA DE NORMAS TÉCNICAS. NBR 10844: Instalações prediais de águas pluviais. Rio de Janeiro, 13p. 1989.

NBR 13969: Tanques sépticos - Unidades de tratamento complementar e disposição final dos efluentes líquidos - Projeto, construção e operação. Rio de Janeiro, 60 p, 1997.

BAZZARELLA, B.B. Caracterização e aproveitamento de água cinza para uso nãopotável em edificações. 2005. 165 f. Dissertação de Mestrado. Vitória: Universidade Federal do Espírito Santo, 2005.

BEGOSSO, L. Determinação de parâmetros de projetos e critérios para dimensionamento e configuração de wetlands construídas para tratamento de água cinza. 2009. 53 f. Dissertação de Mestrado. Campo Grande: Universidade Federal de Mato Grosso do Sul, 2009.

BRAGA, E.D. Estudos de reuso de água em condomínios residenciais. 2009. 144 p. Dissertação de Mestrado. Itajubá: Universidade Federal de Itajubá, 2009.

BRASIL. Ministério das Cidades. Secretaria Nacional de Saneamento Ambiental. Sistema Nacional de Informações sobre Saneamento: Diagnóstico dos Serviços de Água e Esgotos -2014. n. 20, 212 p. Brasília, 2016.

CASA DOS HÓLONS. Proposta. Disponível em: <http://www.casadosholons.com.br/proposta/>. Acesso em: 10 maio 2017.

CHRISPIM, M.C.Avaliação de um sistema de tratamento de águas cinzas em edificação de campus universitário. Dissertação de Mestrado. São Paulo: Faculdade de Saúde Pública da USP, 2014.

FERRAZ, M. F.A.; SILVA, E. M. Estudo de Viabilidade de um Sistema de Tratamento para Reutilização de Água em Finalidades Domiciliares Diversas. Revista Eletrônica em Gestão,Educação e Tecnologia Ambiental - Santa Maria (Reget/UFSM), v. 19, n. 3, p. 702-712. set-dez. 2015.

FERREIRA, D.F. Aproveitamento de águas pluviais e reuso de águas cinzas para fins não potáveis em um condomínio residencial localizado em Florianópolis - SC. 152 f. Trabalho de Conclusão de Curso. Florianópolis: Universidade Federal de Santa Catarina, 2005.

GALBIATI, A.F. Tratamento domiciliar de águas negras através de tanque de evapotranspiração. 2009. 38 f. Dissertação de Mestrado. Campo Grande: Universidade Federal de Mato Grosso do Sul, 2009. 


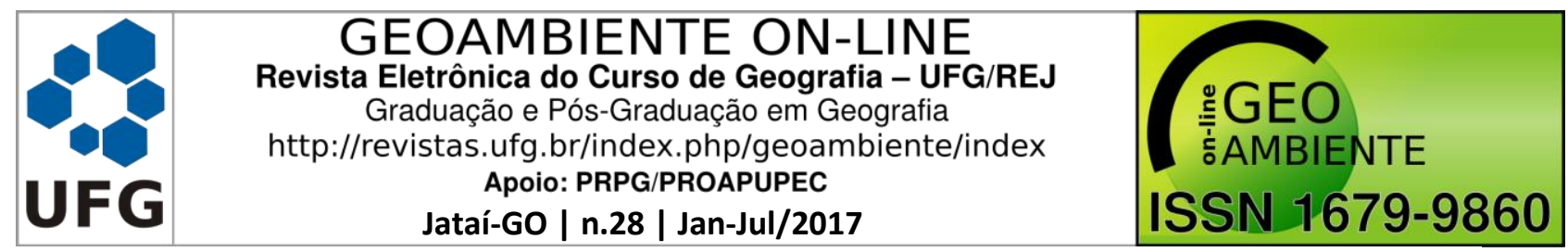

GOMES, B.G.L.A. Tratamento de esgoto de pequena comunidade utilizando tanque séptico, filtro anaeróbio e filtro de areia. Dissertação de Mestrado. Campinas: Faculdade de Engenharia Civil, Arquitetura e Urbanismo da Unicamp, 2015.

HAFNER, A.V. Conservação e Reuso de Água em Edificações - experiências nacionais e internacionais. 2007. 177 p. Dissertação de Mestrado. Rio de Janeiro: Universidade Federal do Rio de Janeiro, 2007.

HESPANHOL, I. Um novo paradigma para a gestão de recursos hídricos. Estudos Avançados, São Paulo, v. 22, n. 63, p. 131-158, 2008. DOI: http://dx.doi.org/10.1590/S010340142008000200009.

KNUPP, A.M. Desempenho de um sistema composto por um filtro anaeróbio e um “wetland" horizontal na produção de água para reúso predial a partir de água cinza clara. 2013. 157 f. Dissertação de Mestrado.Vitória: Universidade Federal do Espírito Santo, 2013.

MAESTRI, R.S. Biorreator à membrana como alternativa para o tratamento de esgotos sanitários e reúso da água. 2007. 117 f. Dissertação de Mestrado. Florianópolis: Universidade Federal de Santa Catarina, 2007.

MARRARA, D.A.F. Filtração lenta em areia, manta não tecida e carvão ativado como pós-tratamento de efluentes domésticos e reuso. 2005. 117 f. Dissertação de Mestrado. Campinas: Universidade Estadual de Campinas, 2005.

MAY, S. Estudo da viabilidade do aproveitamento de água de chuva para consumo não potável em edificações. 2004. 189 p. Dissertação de Mestrado. São Paulo: Escola Politécnica da Universidade de São Paulo, 2004.

Caracterização, Tratamento e Reúso de Águas Cinzas e Aproveitamento de Águas Pluviais em Edificações. 2009. 223 p. Tese de Doutorado. São Paulo: Escola Politécnica da Universidade de São Paulo, 2009.

MEKONNEN, M. M.; HOEKSTRA, A. Y. Four billion people facing severe water scarcity. Science. Advances., V2, N2, p.1 6, 2016.

MONTEIRO, R.C.M. Viabilidade técnica do emprego de "wetlands" para tratamento de água cinza visando o reúso não potável. 2009. 84 f. Dissertação de Mestrado. São Paulo: Escola Politécnica da Universidade de São Paulo, São Paulo, 2009.

MURAKAMI, M.F.; MORUZZI, R.B. Avaliação do amido natural como alternativa simples para tratamento de águas pluviais para fins de aproveitamento não potável. Teoria e Prática na Engenharia Civil, n.20, p.1-13, Novembro, 2012. 


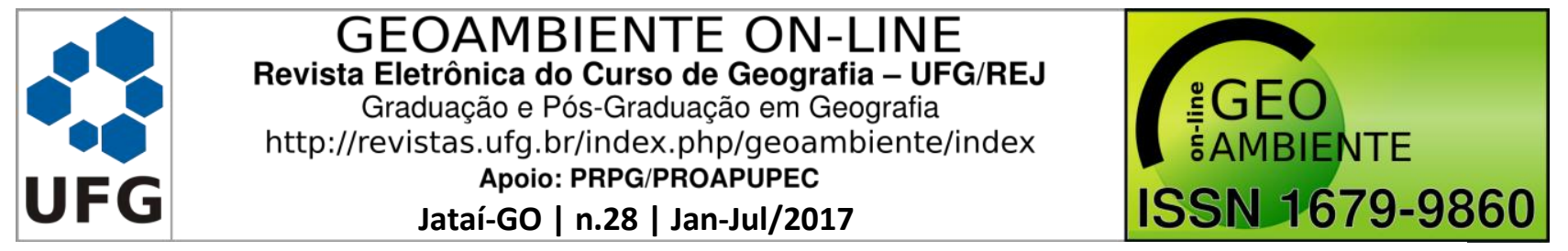

NIREMBERG, L.P.; REIS, R.P.A. Avaliação do desempenho de sistema de reuso de água de uma edificação unifamiliar em Goiânia - GO. Revista Eletrônica de Eng. Civil - REEC, n. 1, v. 10, p. 1-13. 2010.

PANSONATO, N. Tratamento e reuso de água cinza utilizando wetlands construídos e desinfecção solar. 2010. 86 f. Dissertação de Mestrado. Campo Grande: Universidade Federal do Mato Grosso do Sul, 2010.

PETERS, M.R. Potencialidade de uso de fontes alternativas de águas para fins não potáveis em uma unidade residencial. 109 f. Dissertação de Mestrado. Florianópolis: Universidade Federal de Santa Catarina, 2006.

PERTEL, M. Caracterização do uso da água e da energia associada à água em uma edificação residencial convencional e uma dotada de sistema de reuso de águas cinza. Dissertação de Mestrado. Vitória: Universidade Federal do Espírito Santo, 2009.

PHILIPPI, L.S; SEZERINO, P. H; PETERS, M. R; LAPOLLI, F. R. Reuso combinado de águas cinzas (greywater) e água da chuva em uma unidade residencial.7 p. XXIII Congresso Brasileiro de Engenharia Sanitária e Ambiental. ABES: Campo Grande, 2005.

PHILIPPI JR, A.; MALHEIROS, T.F. Saneamento e Saúde Pública: Integrando Homem e Ambiente. In: PHILIPPI JUNIOR, A. (Ed.). Saneamento, Saúde e Ambiente: Fundamentos para um desenvolvimento sustentável. Barueri: Manole, p. 3-31, 2005.

PIRES, J.D.T.S. Reúso de água e aproveitamento da água de chuva como fontes alternativas em propriedades rurais. 2012. 140 p. Dissertação (Mestrado em Engenharia Ambiental) - Universidade Federal de Santa Catarina, Florianópolis, 2012.

RAMPElotTO, G. Caracterização e Tratamento de Águas Cinzas Visando o Reúso Doméstico. 2014. 117 p. Dissertação (Mestrado em Engenharia Civil) - Universidade Federal de Santa Maria, Santa Maria, 2014.

RAPOPORT, B. Águas cinzas: caracterização, avaliação financeira e tratamento para reuso domiciliar e condominial. 2004. 85 f. Rio de Janeiro: Ministério da Saúde/ Fundação Oswaldo Cruz/ Escola Nacional de Saúde Pública, 2004.

SANTOS, H.V.R. Reuso não potável de água em edifícios. 2012. 51 f. Dissertação (Mestrado em Planejamento e Gestão Ambiental) - Universidade Católica de Brasília, Brasília, 2012.

SARNAGLIA, S.A.A. Desempenho de um "wetland" vertical aplicado ao tratamento do efluente de um filtro anaeróbio em uma estação de tratamento de águas cinzas claras 


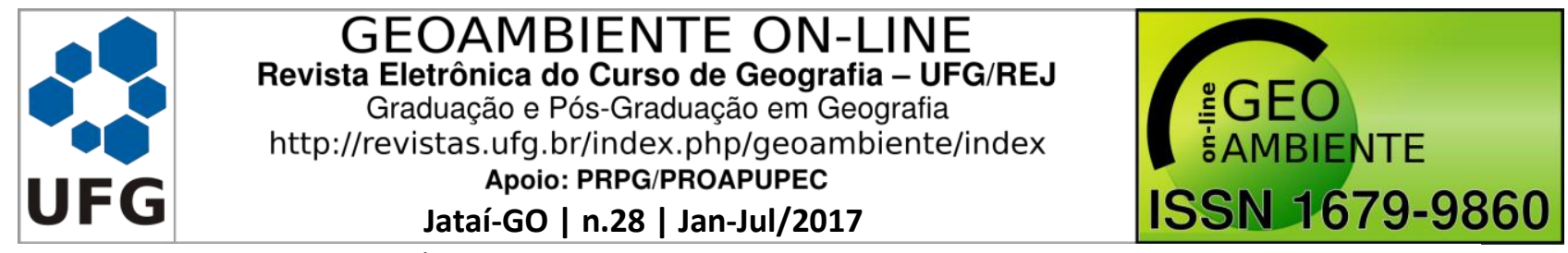

visando o reuso não potável em edificações residenciais. Dissertação de Mestrado. Vitória:

Centro Tecnológico da UFES, 2014.

SEIBERT, A.L. Proposição de um sistema envolvendo Processos Oxidativos Avançados para o tratamento de efluentes residenciais visando o reuso. 2012. 94 p. Dissertação (Mestrado em Ambiente e Desenvolvimento) - Centro Universitário Univates, Lajeado, 2012. SELLA, M.B. Reúso de águas cinzas: avaliação da viabilidade da implantação do sistema em residências. 2011. 87 f. Trabalho de Conclusão de Curso (Graduação em Engenharia Civil) - Universidade Federal do Rio Grande do Sul, Porto Alegre, 2011.

SILVA, M.A.; SANTANA, C.G. Reuso da água: possibilidades de redução do desperdício nas atividades domésticas. Revista do CEDS: Periódico do Centro de Estudos em Desenvolvimento Sustentável da UNDB, São Luís, v.1, n.1, ago./dez. 2014.

SOARES, A.L.J. Conceitos básicos sobre permacultura. Brasília: MA/SDR/PNFC, 53p. 1998.

SOUZA, A.F.S. Diretrizes para implantação de sistema de reuso de água em condomínios residenciais baseadas no método APPCC - Análise de Perigos e Pontos Críticos de Controle: Estudo de Caso Residencial Valville I. 2008. 176 p. Dissertação de Mestrado. São Paulo: Universidade de São Paulo, 2008.

TONETTI, A,L; CORAUCCI FILHO, B; NICOLAU, C,E; BARBOSA, M; TONON, D.. Tratamento de esgoto e produção de água de reúso com o emprego de filtros de areia. Engenharia Sanitária Ambiental., Rio de Janeiro, v. 17, n. 3, p. 287-294. set. 2012.

VALENTINA, R.S.D. Gerenciamento da qualidade e da quantidade de água cinza em uma edificação residencial de alto padrão com vistas ao seu reuso não-potável. Dissertação de Mestrado. Vitória: Universidade Federal do Espírito Santo, 2009.

VARGAS, G.D.L.P. Tratamento terciário de esgoto sanitário através de Processos Oxidativos Avançados para a obtenção de águas de reuso. Tese de Doutorado. Florianópolis: Centro Tecnológico da UFSC, 2008.

VAZ, L.O. Avaliação do risco microbiológico decorrente do reuso de águas cinza em uma edificação residencial de alto padrão. Dissertação de Mestrado. Vitória: Centro Tecnológico da Universidade Federal do Espírito Santo, 2009.

ZOLETT, E. R.; JABUR, A. S.; SILIPRANDI, E. M.Uso de polímero natural a base de Tanino (Tanfloc) para o tratamento de água para o consumo humano. In: XVII SEMINÁRIO DE INICIAÇÃO CIENTÍFICA E TECNOLÓGICA DA UTFPB, Pato Branco. 2012. 